\title{
How Science Communication Delivers Meaningful Frameworks About Industry 4.0 to the Public Sphere
}

\author{
Murat Can Becerir and Lutz Peschke ${ }^{(\bowtie)}$ \\ Department of Communication and Design, \\ Bilkent University Ankara, Ankara, Turkey \\ \{can. becerir, lutz.peschke\}@bilkent.edu.tr
}

\begin{abstract}
With the emergence of new media and interactive media technologies, the mediatized transformative process began. Specifically within the science communication context, the way we perceive issues transformed drastically. With the mediatization of forms of understanding and literacy, the public perception towards many topics, including environmental sciences has gained recognition. This research paper will be focusing on the connection between Industry 4.0 and science communication. By making a valuable contribution to the communication process through constructing a bridge between the industry and the general public, science communication provides a smooth and effective transition of mutually beneficial relationships. This paper concentrates upon the notion of sustainability and its relevance to the industrial revolution, which is also known as Industry 4.0. The paper will be exploring the ways in which how humanity can stay within the safe operating limits with the existing technology and resources. By taking into consideration the notion of sustainability, the paper will attempt to discover possible ways that how people can construct their discourse on the big framework where everything is interconnected to one another. By meaning, Industry 4.0 indicates the connection between automation, computers, smart technologies and the cloud system in which the flow of information has increased in unprecedented levels. Since Industry 4.0 is already happening and has an immense impact on our lives, science communication plays a big part in generating the accessible and relatable message of the implications regarding the age of Industry 4.0. From the automobile industry to the electronic products that we use every day, the majority of the markets use renewable energy in order to lower the costs of production and increase their profits. A disruption in the sustainable development of any given society may cause irreparable damages which can result in colossal economic and political instability. Hence, science communication plays a vital role in terms of providing an understanding of possible pros and cons regarding the practices of the industrialists and the business world. Since it can be quite hard to comprehend the full scale of the consequences of technical occupations and practices, science communication will be the vanguard in terms of constructing a meaningful framework for the general society. This paper will explore what might happen in the lack of understanding of sustainability in Industry 4.0 through renewable energy consumption. Particularly, how a situation looks like when a country experiences a huge setback for its economy, massive loss of life and property in an unsettled global economy. What kind of a
\end{abstract}


scenario would people witness with a disruption in one part of the world, in a world of interconnected production of supply chains that stretch across the world? Therefore, this paper will explore the possible implications of Industry 4.0 through renewable energy consumption on a grand scale.

Keywords: Sustainable development goals $\cdot$ Renewable energy $\cdot$ Industry $4.0 \cdot$ Science communication

\section{Introduction}

The world in which we are living is unique in relation to its era. In the status quo, it is possible to argue that we live in a global village where everything is interconnected with one another. The uniqueness of this interconnectivity is primarily derived from the recent technological advancements. This era of interconnectivity is also known as "Industry 4.0". Equally significant, the topic of renewable energy for sustainable societies is fiercely debated not only amongst the academic realm but also in the governmental and business world. For this reason, this paper will attempt to establish a relationship between Industry 4.0 and renewable energy through the medium of science communication. The research will be investigating what kinds of knowledge can be delivered to the public sphere through science communication in relation to the notions of Industry 4.0 and sustainability? This paper asserts that science communication is a pivotal phenomenon in terms of informing and delivering meaningful insights regarding Industry 4.0 to public sphere. It is vital to recognize the role that science communication plays when it comes to conveying particular messages to a targeted audience. Science communication is the essential medium in which experts of the relative fields desires to educate masses on particular subjects. This paper will construct a framework where the readers/audience will become familiar and even maximize the utility of the notions such as sustainability, renewable energy, Industry 4.0 and the Public Sphere.

\section{Implications of Industry 4.0 Through the Lens of Experts}

In order to delineate how Industry 4.0 can have an immense impact on the welfare of the society, the Boston Consulting Group in Germany conducted research. They found four different ways in which Industry 4.0 will be highly influential in the industrial expansion and improvement for Germany. The first stage they discovered was Productivity. BCG experts concluded that there is an increasing number of companies that are embracing Industry 4.0 applications. According to Rüßmann et al. [1] a growth of up to 150 billion dollars amongst the German manufacturing. This growth will be possible by maximizing the utility of sustainable systems. Secondly, revenue growth proved to be a significant factor which will affect the economy in Germany. BCG proposes that revenue growth will be encouraged through the Industry 4.0 applications. Within the foreseeable future, customer's are being expected to demand more stylized and customized products for themselves in which will require more enhanced 
equipment for the manufacturers to produce such complex goods. As a result, an estimated additional 30 billion euro's will be generated which is considered as a substantial amount for the revenue growth. In fact, this increase also represents $1 \%$ of Germany's GDP.

The third way in which the effect of Industry 4.0 will be observed will be in is employment. BCG experts propose that in alignment with the revenue growth, the employment rate will be increasing approximately $6 \%$ within the next decade. Not only the rate will increase $6 \%$ in general, but also particularly in the technical/engineering fields, the rates will even go further. In accordance with the new technologies which is emerging with Industry 4.0, the on-demand skills such as IT are also becoming more popular. Thus, more employees will be needed to serve in this area and employers will be creating new fields to meet the needs of the newly emerging business sector. Employing more people even by theory, simulates economic prosperity within a society since it means more people will be able to afford purchase goods and manufacturers will be sustaining their businesses. Finally, as the fourth-factor investment plays a key role. BCG experts assert that German manufacturers will be investing an estimated amount of 250 within the next decade.

\subsection{Production and Sustainability}

It's worthwhile to note that the growth and stimuli of the private sector in relation to Industry 4.0 will be affecting every stage of the production. From the design phase to the after sales/marketing, the shift from the conventional way of conducting business to a virtually endless digital network will be vital to observe. With the agency delivered by enhanced IT systems, the production processes will be fully optimized through the integration of them to each other. As a result, in the new system, the production systems will be fully automated in which means a much more effective and sustainable production culture. Moreover, one will be able to preserve the energy surplus and use the exact unit of energy needed for a particular type of production.

Industry 4.0 will be providing humanity with a new set of tools which will revolutionize the way we conduct our capital affairs consumption habits and consumer culture. Notions such as quality, speed, flexibility, and productivity gain a whole new level with the new age which is upon us. Improving the effectiveness of these notions leads to a more productive future, lucrative business ventures and customers who can afford to purchase the goods since their cost will be cheaper. Industry 4.0 will be constructing the base for the upcoming new business models, production types, diverse jobs, and various different innovations.

The sections aforementioned in relation to Industry 4.0 proves to be a vital point both for ordinary people and the private sector. For this reason, science communication has to be incorporated into these phenomena in such an effective way that people in the public sphere can be aware of the innovations that will change their lives. Raising awareness of the issue of Industry 4.0 which will also be connected to sustainability enables us to enhance our comprehension towards our future selves. Hence, highlighting the crucial importance of science communication in terms of reconstructing our mentality towards technology, production, and their effects will be beneficial for people who can live their lives in the best possible way. Science communication can serve as a 
tool for informing the public sphere on imperative topics which will have a considerable amount of impact on our lives.

\section{Theoretical Aspect "Public Sphere"}

Before focusing on concrete events and case studies, it is important to be familiar with the concept of the Public Sphere. Habermas asserts that "a realm of our social life in which something approaching public opinion can be formed" [2]. Today, the public sphere largely consists of media which includes the internet, tv and print materials. In the earlier ages, when people had no knowledge regarding the internet or the tv, the medium of the sphere was different. In the $21^{\text {st }}$ century, the active public sphere consists of the world wide web, TV and screen technologies in general. With the advancement of technology and innovations, our public sphere expanded to a much larger extent. By connecting to the internet, one gains access to the global village in which we're living in.

Media should not be merely associated with TV, but also linked with the internet which revolutionized the concept of media itself. Anyone who has access to the internet also gains access to a platform in which they can connect with a global community and participate in a new form of the public sphere. Since Industry 4.0 is significantly related to internet technology, Internet of Things (IoT) to be more specific, it is crucial to recognize the significance of the relationship between the internet and Industry 4.0. Hence, this paper will be referring to matters in the grand scale of media considering the public sphere.

\section{Sustainability as a Concept}

Moreover, sustainable development is one of the core themes in which this paper will be focusing on. In order to provide a general understanding of sustainability, it would be useful to overview the sustainable development goals (SDGs) of the United Nations. The total 17 goals encapsulate the Essentials for the transformation of the world including zero hunger, no poverty, gender equality, affordable and clean energy, sustainable cities and communities and so on [3]. In a general sense, these goals exist with the purpose of creating a sustainable and highly functioning environment. and leaving it as a heritage to the new generations to come. Jeffrey Sachs [4] defines the age we're living in as "We have entered a new era. Global society is interconnected as never before. [...] I suggest that we have arrived in the Age of Sustainable Development". in his book the Age of Sustainability.

In order to illustrate the state of public awareness to sustainability, this paper will be focusing on the intersection of public engagement and Industry 4.0. To accomplish this, we will be focusing on science festivals within the scope of public engagement with particular themes and issues. Concrete case studies are beneficial for the sake of delineating how the public engages with certain topics in the public sphere. 


\section{Science Communication as a Concept}

In order to initiate a discussion and provide an enhanced form of understanding towards Industry 4.0 through science communication, one should focus on science and technology studies. Equally significant with science communication, science and technology studies (STS) puts forth worthwhile notions which support our comprehension towards innovation, technology, research, and responsibility. According to Stilgoe and Guston, STS had the primary function of providing an understanding of the course of the results and process of science and technology management. RRI, which stands for Responsible Research and Innovation sets a couple of goals in order to provoke a meaningful discussion. "First, on the environmental implications and applications of nanotechnology and, second, on integrating social sciences, as a way of divining and making sense of societal concerns, into the nano-scale science and engineering research itself" [5]. The goal is to establish a bridge where nanotechnology, social sciences, engineering, and societal concerns can be discussed and made sense of on the common ground. Stilgoe and Guston assert that the notion of innovation is being interpreted as the offsprings of conventional presumptions concerning scientific autonomy and authority.

"Revealing the normative models of publics that are being enacted in science and policy, understanding and challenging "expert" presumptions about relevant public issues, describing the diversity of other cultures in which understandings might differ and be able to contribute, and, finally, putting this in the context of historical and philosophical perspectives on science as public knowledge" [5]. By comprehending and challenging general knowledge about public issues, STS aims to deliver new, meaningful and creative ways of rethinking pressing matters at hand. Concentrating on the different cultural contexts can be considered as a pivotal aspect since meaning can be derived from many different cultural aspects of a given society. Hence, STS underscores the presence and the functionality of responsible innovation which is both an adversary and an opportunity where the conventional way of conduct and innovative way of practicing matters can be closely studied.

\subsection{Science Communication in Germany}

The relation of science and public was subject to a big change in the course of the last century. This was mainly associated with the temporal development of science. In the 17 th and 18th century, neutral scientist started to work on a view on the world which differed from the religious dogmatized ideology of that time. But these activities were only possible with the help of patronages which could only be provided by the aristocracy. For instance, Galileo served at the court of the Medicis which gave him the status of an independent researcher. In principle, he was the first researcher in the modern understanding [6]. Until that time, the society did not know the differentiation of different scientific subjects neither the separation of scientists and non-scientists. Hochadel called the 18th century the "golden age of lay science" [7]. The central goal was to present experiments with big surprise effect to a broad and amazed audience. With increasing differentiation of science, scientific work moved increasingly to enclosed laboratories which were specially built for those issues. The public 
participation and attestation of results were complicated by the aid of precise measurements which become increasingly an important component of scientific research. This shift of science to enclosed laboratories changed the science communication crucially. On the one hand, results were primarily shared and discussed with peers of the collaborative laboratory. On the other hand, spectacular results and discoveries were presented to the public in a kind of secondary communication [8].

The displacement of scientific productions to an enclosed location, where only selected people and peers had access to was conventionally called professionalization of science (ibid.). In a way of countermovement, there arose a movement of popularisation of natural science in the 19th century.

Associations were founded which were supported and funded by well-educated and interested citizens. Popular scientific presentations and lectures were organized and institutions were established, where lay people could execute their scientific work. One example is the Urania in Berlin where Alexander von Humboldt presented his studies in his famous lecture about the cosmos to a diverse audience in 1827/28. Among the audience was King Friedrich Wilhelm III as well as master bricklayers [9].

The term popularisation is grounded in the meaning of popularity which is understood in term of intelligibility, for the people, etc. [10]. However, from the very beginning, this concept stuck to the image of the shallow and the trivial. Kretschmann worked out that Liebig repudiated all popularising forms of representations in is Chemische Briefe (Chemical Letters). He stated that the diverse connotations of the term popularisation complicate the modeling significantly. According to him, older approaches regard popularisation as knowledge transfer in a hierarchical way from a small circle of experts to a non-specific public. It means the imparting action remained oriented towards academic science production. The firstly academically generated knowledge will be later communicated to the lay people in a simplified way. However, the audience was involved neither in the production nor in the distribution of knowledge (ibid 21). Daum talks about a "diffusionistic model" in this context [11]. In reply to this model, Shinn and Whitley offered an interactionistic view, where scientists, popularisers, and public are the actors of interactive communication between producers and recipients [12]. Popularisers are almost media-based actors. In 1851 the first world exhibition was executed in London. It was a new format of popularisation of science and technology. Within the scope of the technological progress, it should be demonstrated to the broad western public that the technological progress enhanced the living conditions in the world and that the still continuing progress effects the conditions in an ongoing positive way.

But at the end of the 20th century, there was a big change in the societal acceptance and interest in science and technology. Schmidt compared the relation of (not only) the young generation to science with the meeting of Jim Knopf and Lukas the locomotive driver with the "pseudo-giant" Mr. Tur Tur in Michael Ende's same-named novel [13]. The main feature of the pseudo-giant was the phenomenon that he did not become bigger the closer Jim and Lukas came to Mr. Tur Tur but smaller [14]. This described phenomenon is completely unrealistic from the point of view of a natural scientist since it contradicts all observations in nature. But with a look from outside to the system natural science, the science itself corresponds with the feature of Mr. Tur Tur. Young people often do not decide to study science and technology because they are too afraid 
of the complex discipline. The reason is almost the fear of the distance to the subject. But the more people are engaged with science the more they get the feeling of their own potential to manage the complex problems of science and the fear of dealing with disappears [15].

According to the model of Shinn and Whitley, science communication in the sense of science popularisation means that science and society have to be involved in the process of popularisation in the same way. For a long time, the opinion of science and especially of scientists was that the public has to approach to science. Otherwise, the risk of trivialization of science and the decrease of the educational level would be significant. This understanding was very common in the institution of science. It enabled an undisturbed study for the scientists. But at the same time, a kind of ivory tower arose around the scientists which they left rarely. It was not necessary to leave the ivory tower. Economical enterprises will fail on the market if they would develop and design a product which is not equivalent to the need of the consumers. But as opposed to economic enterprises, scientists are spared the failure, since scientists proceed their research always under the condition not to know the result of their activities. Even a negative result is understood as positive recognition. Accordingly, there was no direct need to get in contact with the public. The communication and discourse happened in a closed shop which developed an own "language". The internal audience, the peer was regarded as the relevance audience [15].

Within the scope of the dramatic drop in the numbers of student beginners in science in Germany at the end of the 20th century, the scientific community has to rethink its concept of science communication. The drop was an indicator that the voluntary engagement with science disappeared. This caused a fatal cognitive discrepancy of the society between the products of science which are regarded as highly systemically important, e.g. smart technology, and the interested in the scientific disciplines which are the basis of the products. To counteract this discrepancy, leading research institutions and associations, universities as well economy which was represented by the Stifterverband für die Deutsche Wissenschaft and the Federal Ministry for Education and Research negotiated a memorandum in 1999. The signatories agreed and committed oneself to enable the dialogue of science with society. Systems of incentives should be established which encourages scientists to get in dialogue with the society without losing their scientific reputation [16].

The process of the described public understanding of science and humanities (PUSH) was methodically introduced by a process of fuzzification of science [17]. It is understood as activities which transform precise descriptions of the scientific world into communicable hermeneutic forms to enable the connection of scientific phenomena with experiences of the life world and to support the process of reception (ibid., 78). This kind of scientific communication was a completely new and unfamiliar experience for the very most of German scientist. They were used to present their research topics to a peer audience. According to Neidhardt, science in Germany was used to loneliness and freedom [18]. But now they stood in pedestrian areas and shopping malls and presented their research activities to a shopping public which primarily did not come to this location to participate in science. When the Federal Ministry of Education and Research announced the "Year of Physics" in 2000 which was executed by iserundschmidt - agency for science communication, the resentments among the scientists 
were very high to present their scientific research in the way described above. But in the course of the year of physics, they realized that this process of science communication for the public changed additionally the communication process between the peers. Scientist felt satisfaction during their presentations to a non-scientific public [19]. Schmidt stated that within the scope of estimation of the initiative "Science in Dialogue" a modernisation of the scientific process was started [13]. The consequence of the turn was a sustainable redevelopment of the communication policy: Scientific institutions turned from an object of public discourses to an active player (ebd.: 38). The feedback of the turn in Germany in the public was significant and it was newsworthy in the science magazine nature [20].

But the objective to place science in media and to make science accessible for a broad public was discussed in a controversial way. While Schmidt understands the steady media presence as a requirement to guarantee the return of science to the society, Weingart sees an abyss between professional science and the communicators in the media. He states that medical criteria for news values contradict the media criteria for scientific integrity. According to him, the increasing mediatisation of societal communication generates an increasing need for entertainment among the non-professional audience which is served by the conditions of media productions. It proceeds in a way that the media follow the prevalent dramaturgic formats considering the narrative, temporal and visual design a format [8, 21]. But the science edutainment concept provoked criticism and defensive attitudes. According to Weingart, Public Understanding of Science is sales campaigns which are directed to the mass media attention for event and entertainment, because they assume an unstructured and unspecific audience [8]. Science exhibitions follow just the principle of edutainment since the claim is not only education but also entertainment. He takes for granted that education is not the only value in the mediatised society. The media are forced to generate special kicks to reach new clients (ebd. 25). As a consequence, the specificity of science disappears because of the indistinguishability of conventional media formats. He brings up the question, which consequences regarding the legitimacy of science will arise. According to Weingart and Neidhardt, the safeguarding of scientific talents will not be reached with help of PR campaigns, but the setting the focus on peers which are resulted in the context of research and education in universities. The most important duty of scientists for the public will proceed in the universities and students are the most important audience which is mainly mistreated by the educational system [8, 18].

In contrast, Kretschmann stated that the ambitions of popularisation in Germany are more criticised the more entertainment the format consists of. This problem does not exist in the Anglo-Saxon countries [10]. He points to the fact that research, politics, and economy demand knowledge reception of the public which only can be proceeded voluntarily. But the broad public will bring this performance only when the media offer a certain degree of entertainment. Hence, the basic need of divertissement, relaxation, and dissipation has to be considered in the concept of science popularisation. Newest studies show that communication processes are more creative and effective than instructions which are based on pure information (ibid.). 


\subsection{IdeenExpo in Hanover}

The IdeenExpo is a science festival which occurs every two years on the fair trade area in Hanover/Germany. It was initiated in 2007 by the Minister-President of LowerSaxony at that time Christian Wulff. He was inspired by the IdeenPark, which was executed 2006 on the Expo Plaza close to the fair trade area. The organizing company was ThyssenKrupp. Member of the supervisory board of IdeenExpo is the employers' association NiedersachsenMetall. Sponsors of the science festival are enterprises, like Volkswagen or Sennheiser electronics. The first IdeenExpo 2007 was designed as a big technique show with 250 exhibits, workshops, experimental presentation, and talk events. The center of IdeenExpo was from the beginning until today an open-air science show on nine days at noon time where the TV moderator presented exciting and fascinating highlights of science. The IdeenExpo started with 160,000 visitors in 2007 and increased every year to 360,000 visitors in 2017. The aim of the science festival is to attract young people with science and technology. The target group is not only potential student beginners but also apprentices. Accordingly, the exhibition and interactive area dominantly consist of crafting and hands-on experiences. Besides, show acts are designed to introduce in jobs based on formal training which are widely unknown as a technical profession, e.g. mechatronic technician or skyscraper windows cleaner. Consequently, the science festival does not limit its focus on potential academicians but includes also students who will finish school after middle school graduation.

In the context of public understanding of science in Germany, with the establishment of IdeenPark and IdeenExpo, it was the first time that an economic entity realized a science festival with the goal to attract young people for science. It can be understood as an executive step to fulfill the self-commitment of the economy to invest in public understanding of science formates which politics, economy, and academia signed within the scope of the symposium "Science and Society" in Bonn in 1999 [16]. After 2007, the successful penetration of dialogic exhibits in the meaning of public understanding of science could be observed. While 2007 the event was predominantly designed as a technique show, in 2017 the hands-on experiments in the context of joining in formates increased. Additionally, the IdeenExpo contributes to compensating the significant mistakes of the $1970 \mathrm{~s}$ and $1980 \mathrm{~s}$ that the educational and governmental system created a system to increase the chance for children of families with low and middle income to study since university education was regarded as the chance to overcome educational and job discrimination. As a consequence, the majority of children were forced to study at universities and after 10 until 20 years the lack of technicians, plumbers, electricians and other workers based on formal trainings became significantly high. With the science festival IdeenExpo, young students from middle and high schools had the chance to learn about job perspectives beyond academic education. 


\section{Industry 4.0 as a Phenomenon}

Industry 4.0 marks our age as a unique era in which undergoes a significant transformation through an unprecedented increase in the level of interconnectivity. What humanity already had was the connection between people and machines. With the emergence of Industry 4.0, the World witnessed much broader connectivity encapsulating both human-machine and machine to machine connectivity. "Full automation and digitization processes, and the use of electronics and information technologies (IT) in manufacturing and services in a private environment" [22]. Through being fully automated and digitized, our age has been revolutionized. When one investigates the recent changes that took place in people's daily lives, it becomes quite visible to identify the changes and revolutions. Considering that people are able to order food directly from their computer or smartphone to their fridge and being able to order various different kinds of goods from any location on the globe to their doorstep will indeed have a significant impact regarding the reconstruction of small and medium scale corporations.

For the sake of demonstrating how Industry 4.0 leads to the future of factories and smart factories which is connected to efficiency as well, its worthwhile to concentrate on Roblek's input on factories. "The smart factory will be more intelligent, flexible, and dynamic. Manufacturing will be equipped with sensors, actors, and autonomous systems. Machines and equipment will have the ability to improve processes through self-optimization and autonomous decision making" [22]. With these improvements, it's possible to have a more efficient and sustainable production system which would benefit both the customer (affordability) and the manufacturer (cost efficient).

"Industry 4.0 will be characterized by greater flexibility in the production process. It will be possible to create products for-fitted to the needs of a single client at a relatively low marginal cost" [22]. Hence, the corporations and manufacturers will be benefiting from the low marginal cost which will be projected on the consumers as well. With this technological revolution, the goal of achieving sustainable economic growth within society seems to be more feasible. Furthermore, Roblek puts forth that smart cities will be benefiting significantly from these improvements. The existence and enhancement of smart cities are considered to be the offspring of IT technology and data-based systems. "Universality in industrial applications: Internet of Things, Internet of Services, Internet of Media, big data, communications inter-machines and cyberphysical systems using interoperability, decentralization and full virtualization certainly will affect different course of many phenomena than is apparent from past experience" [22]. As stated by Magruk, today and in the foreseeable future the way we communicate with each other and with our environment will be drastically affected [23, 24].

\subsection{Industry 4.0 and Renewable Energy}

Renewable energy is being discussed in a wide range of bodies including governmental institutions, the private sector and in the academic circle. In fact, this demonstrates the severity of the situation globally. Increasingly, more and more funding is being allocated by governments and companies. In academia, Universities and academic conferences grant a separate funding/scholarship to encourage research on renewable 
energy and how it can be more efficient and accessible worldwide. Since this situation is being dealt within the era of Industry 4.0, it becomes even more significant to identify which entities are benefiting from renewable energy and in what ways can it contribute to the welfare of the society. In general, smart goods manufactured by smart factories use smart grids as a source of energy.

"A smart grid dynamically matches the energy generation of suppliers using renewable energies with the energy demand of consumers, e.g. smart factories or smart homes, by using short-term energy storages for buffering. Within a smart grid, energy consumers and suppliers can be the same" [24]. In the status quo, we have the tendency to identify multiple different entities as smart. The reason for this is that with the current technological capabilities and advancements lead both the consumers and companies to name today's goods as smart to demonstrate their various skills and efficiency. By utilizing the short term energy storages, it seems that the smart entities are maximizing their efficiency. Stock and Selinger asserts that by being involved in self-sufficient supply as well as taking advantage of the supply brought by the external smart grid, the factory will be existing both as a consumer and as a supplier. This will be all made possible through the factories increasing usage of renewable energy resources.

\subsection{Economic, Social and Environmental Aspects of Industry 4.0}

By allocating resources effectively such as materials, products, and energy, indeed economic benefits are unavoidable. Stock and Seliger argue that in social terms, it is possible to enhance the efficiency and productivity of the workers by incorporating the latest ICT technological with the virtual reality headsets. "Sustainable business models significantly create positive or reduce negative impacts for the environment or society or they can even fundamentally contribute to solving an environmental or social problem" [24].

Thus, sustainability has such an impact that it can radically alter the shape of the business itself which also means that it can regulate the flow of it too. In other words, sustainability has the agency to control economic growth as well. By allocating the right amount and type of material to the right place, sustainability also affects the environment as well. In essence, sustainable systems do not require any external resources since they can generate the necessary energy/power within themselves. Therefore, achieving sustainable development is vital for the existence and evolution of Industry 4.0.

\section{Conclusion}

As the paper deals with various notions such as sustainability, renewable energy and Industry 4.0, we have witnessed how crucially significant they are for us today and for the foreseeable future. Hence, science communication needs to be used as effectively as possible to communicate with people about relevant content. The communication has to be so effective that an ordinary person in the public sphere should be able to comprehend the basic concepts alongside with its pros and cons. Thus, it would be 
possible to pave the way for enhanced comprehension regarding our surroundings. Possessing knowledge about Industry 4.0, sustainability, renewable energy and its implications for humanity will enable us to live our lives more wisely and efficiently.

Acknowledgment. This research paper was generated within the scope of the project "POWER: Empowerment of Youth on Renewable Energy for Sustainable Societies", which is funded by the Erasmus+ Program of the European Union 2017-3-TR01-KA205-048402.

\section{References}

1. Rüßmann, M., Lorenz, M., Gerbert, P., Waldner, M., Justus, J., Engel, P., Harnisch, M.: Industry 4.0: the future of productivity and growth in manufacturing industries. Boston Consult. Group 9(1), 54-89 (2015)

2. Habermas, J., Lennox, S., Lennox, F.: The public sphere: an encyclopedia article (1964). New German Critique 3, 49-55 (1974)

3. United Nations Development Programme Sustainable Development Goals 2019. https:// www.undp.org/content/undp/en/home/sustainable-development-goals.html. Accessed 14 May 2019

4. Sachs, J.D.: The End of Poverty: Economic Possibilities for our Time. Penguin, London (2006)

5. Felt, U., Fouché, R., Miller, C.A., Smith-Doerr, L. (eds.): The Handbook of Science and Technology Studies. MIT Press, Cambridge (2017)

6. Biagioli, M.: Galilei, der Höfling. Entdeckung und Etikette: Vom Aufstieg der neuen Wissenschaft. S. Fischer, Frankfurt am Main (1999)

7. Hochadel, O.: Öffentliche Wissenschaft. Elektrizität in der deutschen Aufklärung. Wallstein, Göttingen (2003)

8. Weingart, P.: Die Wissenschaft der Öffentlichkeit Essays zum Verhältnis von Wissenschaft Medien und Öffentlichkeit. Velbrück Wissenschaft, Weilerswist, Weilerswist (2005)

9. Orland, B.: Reisen zum Mittelpunkt der Erde. Anfänge und Aspekte einer Geschichte der Populärwissenschaft. Kultur/Technik, vol. 3, p. 48 (1996)

10. Kretschmann, C.: Wissenspopularisierung. Verfahren und Beschreibungsmodelle - ein Aufriss. In Boden, P., Müller, D. (eds.) Populäres Wissen im medialen Wandel seit 1850. Berlin: Kulturverlag Kadmos, Berlin, p. 20 (2009)

11. Daum, A.: Wissenschaftspopularisierung im 19. Jahrhundert. R. Oldenbourg, München (1998)

12. Whitley, R.: Knowledge producers and knowledge acquirers. Popularisation as a relation between scientific fields and their publics. In: Shinn, T., Whitley, R. (eds.) Expository Science: Forms and Function of Popularisation. Springer Science + Business Media, Luxemburg/Berlin (1985)

13. Schmidt, M.: Raus aus dem Scheinriesen-Dilemma. In: Mager, B., Hamacher, H. (eds.) Marketing und Kommunikation von Forschung. Research Goes Public. Köln International School of Design, Köln (2003)

14. Ende, M.: Jim Knopf und Lukas der Lokomotivführer. Thienemann, Stuttgart (2004)

15. Peschke, L.: Wissen sichtbar machen - von der Verbindung des Nützlichen mit dem Schönen. In: Seuser, K. (ed.) Zukunft im Technikjournalismus. Hochschule Bonn RheinSieg, Sankt Augustin (2014) 
16. Stifterverband für die Deutsche Wissenschaft. Dialog Wissenschaft und Gesellschaft. Symposium "Public Understanding of Science and Humanities - International and German Perspectives". Stifterverband für die Deutsche Wissenschaft, Essen (1999)

17. Peschke, L.: Infografiken. Visualität und Wissensaneignung in der mediatisierten Welt. Springer VS, Wiesbaden (2019)

18. Neidhardt, F.: Wissenschaft als öffentliche Angelegenheit. WZB-Vorlesungen 3. Berlin: Wissenschaftszentrum Berlin, Berlin (2002)

19. Lahr-Nilles, E., Wandelt, K.: Eine Stadt aus Licht und Laser/Wissenschaft im Kaufhaus eine gelungene Premiere/“Stein der Weisen”-Physik trifft Kunst. Physikalische Blätter 56 (9), 18-21 (2000)

20. Nature: Germans engage with physics, Nature, vol. 406, p. 6798 (24 8 2000)

21. Donges, P., Imhoff, K.: Öffentlichkeit im Wandel. In: Jarren, O., Bonfadelli, H. (eds.) Einführung in die Publizistikwissenschaft. Paul Haupt, Bern (2001)

22. Roblek, V., Meško, M., Krapež, A.: A complex view of industry 4.0. Sage Open 6(2), 2158244016653987 (2016)

23. Magruk, A.: Uncertainty in the sphere of the industry 4.0-potential areas to research. Bus. Manag. Educ. 14(2), 275-291 (2016)

24. Stock, T., Seliger, G.: Opportunities of sustainable manufacturing in industry 4.0. Procedia Cirp 40, 536-541 (2016) 